ing through the inspection, and, since so few have escaped, it is at least permissible to infer that the incubation period is a short one.

Another and stronger piece of evidence in the same direction is afforded by a table shewing the date of appearance of the disease in persons placed under observation as suspicious either in their own persons or as members of an infected community. If the disease appeared in a person at all, it came as a rule within the first 36 hours, and, as time went on, the probability of its appearance diminished rapidly up to 8 or 9 days. The only exception to this was that it seemed a little more likely to appear on the third day than the second.

The people of Poona do not yet seem to have learnt that the measures of Government in the direction of plague prevention are meant to help them from the clutches of the direst scourge known to man, and not as a means of wanton and purposeless trampling on all they count precious either in the way of custom or religion. The tone of their complaints against the officers of Government, working in their midst, reveals a spirit the more regrettable, as it is shewn by those who would be considered to be among the leaders of educated native thought in India. Mr. Lamb has recently published a strong protest against the cautious and almost childish spirit in which complaints are made against the plague organization ; there is no doubt that, judging from the published samples of these petitions, he is amply justified in his severe and trenchant criticisms. In our opinion the most lamentable feature in the matter is the relaxation of the segregation rules in order to render work at all possible. If what we have read in the daily papers is true, a retrograde step in dealing with plague has been taken, which will sooner or later be regretted by the authorities.

The case of Poona seems bad indeed. We would ask with curiosity,-What kind of Health Officer can be expected for the salary and on the terms that the Poona Municipality advertise? Surgeon-Major J. P. Barry has given us an account of the life-history of a previous Health Officer at Poona. Can it be that the Municipality desire to furnish us with another of the homunculi for a more extended study? The Commissioners will, of course, say that they have no funds to pay a better class of Health Officer, but then the question arises as to whether such impecunious people are fit to be eutrusted with the lives and health of such a place as Poona, and whether, after all, this is not a matter for Government to deal with, seeing how many of their servants are, as residents in Poona, liable to be sacrificed to the now notorious policy of the Poona Municipality.

The Bombay Municipality has not yet found time to give Government its ideas on the new scheme for the improvement of the city; this is significant, as are also the facts that both the Chamber of Commerce and the Port Trust, bodies which represent the cream of the commercial ability of the city, have already aided Government with their criticism and have expressed their cordial recognition of the great need of sanitary reform in the city. Still more ominous was the fact that, when the matter came up for discussion at the Corporation meeting, there was not an overwhelming amount of wisdom in the speeches that were made. Further details were asked for from Government, and the matter was referred to a committee; beyond this, and the expression of fears that the scheme would in some way not explained be an assault on the dignity, \&c., of the Corporation, there was not an attempt to discuss the proposed conversion of the city; but then sanitation is such anuisance!

\section{LONDON LETTER.}

THE serious epidemic of typhoid fever which has recently broken out in the town of Maidstone, Kent, is occupying a large share of the public attention at present. The first notifications of the disease were received on the 11 th of September, and up to the 16 th of that month the daily notifications were few-from 1 to 4 . On that date a sudden rise took place to 27 , and on the 20 th another jump upwards to 121 . The numbers continued high until the end of the month when some abatement was manifest, but cases are still occurring. I observe in this morning's paper that 33 notifications were received yesterday, bringing up the total to 1,619 cases, of which 80 have proved fatal. This is a very serious matter in a town of some 32,000 inhabitants. The epidemic presents a character best described by the term explosive. The early cases betoken differences in the period of incubation, and the sudden rise to a short-timed maximum betokens a common subjection of the susceptible to some special condition of more or less universal prevalence. The prolongation of the epidemic on a less severe scale is probably due to secondary methods of diffusion. The outbreak in short presents all the characters of water pollution by the specific virus: and this has been proved to be the case. The town derived its water from three sources-two of unquestionable purity distributed to the central area and one more liable to contamination to the circumferential quarters. One of the springs from which the latter supply was drawn is in the middle of an unfenced meadow where a number of hop-pickers pitched their camp, and it was subsequently discovered that several of these suffered from enteric fever during their stay in this locality. The distribution of the disease corresponded exactly to the distribution of this supply, and there can be no rational doubt that specific pollution of this water constituted the primary and main cause of this epidemic. 
Everything that is possible is now being done to stamp out the disease and relieve the sufferers; but there are other ways and channels through which the infection of typhoid spread, and the summary extinction of a plague of this sort once set up on a large scale is by no means a simple matter.

Among other means that have been suggested and adopted to some extent to limit the extension of the disease is the injection of antityphoid vaccine according to the method devised by Professor A. E. Wright, M.D., of the Army Medical School, Netley. The object is to "achieve a degree of immunity which shall be equal to or greater than that which accrues to a patient who undergoes and recovers from an actual attack of the disease, and to achieve that immunity without any risk to life or health." For this purpose the typhoid bacillus is cultivated in agar. These cultures are made in 24 hours at blood-heat. They are emulsified by the addition of measured quantities of sterile broth; the emulsion is drawn into sterile glass pipettes, which are sealed and placed in a beaker of cold water which is gradually raised to $60^{\circ} \mathrm{C}$., at which temperature they are kept for five minutes. The material is now tested by inoculating an agar tube in order to prove its sterility. Injections are now made with it, and a local and constitutional reaction is obtained of a mild character. Immunity is proved by the occurrence of agglutination in an emulsion of live bacteria to which some of the serum of the blood of the inoculated subject is added. The immunity so demonstrated seems to be of a high degree and at least equal to that conferred by an attack of the disease as evidenced by the same power of agglutination of the live bacilli by means of blood serum drawn from the convalescent.

A valuable paper describing the process and experiments in detail, drawn up by Professor Wright and his Assistant, Surgeon-Major Semple, will be found in the British Medical Journal of 30th January last. A very interesting point connected with these researches is that the blood of persons who have suffered from Malta fever possesses the same power of agglutinating emulsions of the special bacillus of that disease, and a means of diagnosis of a very accurate description is thus placed in the hands of physicians. Several cases invalided from India have been subjected to this test, and the important result has been gained that this disease appears to be one which is prevalent in India as well as in the Mediterranean. The subject is still in its infancy; but the necessity of carefully studying Indian fever from this point of view is manifest. Clinical observation and bacteriological research must in these days go hand in hand, and the elimination of one other fever from the cloaca maxima of remittent or simple continued fever appears to be a very probable outcome of these investigations. I advise Indian medical men to familiarise themselves with the symptomatology and patho$\operatorname{logy}$ of Malta fever, and to keep a sharp look out for cases in military and civil practice.

The study of tropical diseases is now becoming an important feature in the curricula of many schools. At St. George's, Dr. Patrick Manson made this the subject of his introductory address, and contended with great force of argument and illustration for the need of instruction in the maladies of hot countries by persons who might spend their professional lives in the tropics. $\mathrm{He}$ showed from his own experience that a knowledge of such matters was too often gained at the expense of the patient, after, instead of before, entering on practice. His views have been warmly supported by the medical press, and what Netley does for the military surgeon will probably ere long be done by most civil schools for civil practitioners. At the same time any addition to the already heavy burden of the student's task-work is to be deprecated, and it is an open question whether special instruction in tropical diseases should not be a post-graduate rather than a pre-graduate course. A movement is now on foot to establish a journal of tropical medicine in England. This is an excellent proposal and has my warm approval. Such a publication should not interfere with journals issued in tropical countries but rather the reverse. It would constitute a medium by which the information published in these would reach many practitioners and students who would otherwise remain in ignorance, and would in its turn convey to tropical journals and practitioners observations regarding the after history and treatment of tropical cases in temperate countries which might be of very great service and value to those to whom the early management of these is entrusted.

12 th October 1897.

\section{Service dote.}

Accounts from India point to a practical collapse of the Civil Medical Department in that country. Medical officers and subordinates lent for plague duty by the military medical authorities at Simla, merely as a temporary measure, having had, owing to military exigencies which must be paramount, to return to military duty for the various expeditions, the Head of the Civil Medical Department has no reserve to fall back on, and civiliaus from England have had to be enlisted for plague duty. Surely the Head of the Civil Medical Department might have seen that exigencies such as these would have arisen, and have made timely and adequate provision. Now we are informed that the Civil Medical Department is clamouring for the services of the last batch of candidates for the Indian Medi- 